\title{
Examination of covered amalgamated Leaf Spiral
}

\author{
Samson yohannes ${ }^{1}$, B.K.Rao ${ }^{2}$ \\ ${ }^{1}$ HOD, Department of mechanical Engineering, Maddawalabu University, Ethiopia \\ ${ }^{2}$ Assistant professor, Mechanical Engineering Department, Maddawalabu University, Ethiopia
}

\begin{abstract}
In the present paper, weight reduction is the main criteria in automobile industries. The Leaf Spiral is one of the potential item for weight reduction in automobile as it accounts for ten to twenty percent of the unstrung weight. The automotive industries are showing keen interest in replacing of steel spring with composite Leaf Spiral due to high strength to weight ratio. This helps in achieving the vehicle with improved riding qualities. In the present work an attempt is made to replace the existing mono steel Leaf Spiral of passenger vehicle with amalgamated composite Leaf Spiral. The dimension of a amalgamated composite Leaf Spiral is considered same as that of existing steel spring. In this work three different composite materials were considered for the investigation namely, Composite-1, Composite-2\& Composite-3. These amalgamated composite mono Leaf Spirals have been modeled by considering uniform cross-section, with unidirectional fiber orientation angle for each lamina of a laminate. Modeling of both mono steel Leaf Spiral and amalgamated composite Leaf Spirals was done using CREO software. Static analysis of both steel and amalgamated composite Leaf Spirals made of three different materials was carried out at predefined static loading condition using commercially available package. The design constraints considered in this investigation were stresses and deflections. The induced stresses and deflections have been compared with the permissible limits of material selected. Modal analysis is also been performed for mono steel spring and amalgamated composite Leaf Spiral to determine their natural frequencies and mode shapes. Finally a comparison is made between steel spring and amalgamated composite Leaf Spiral made of three different materials in terms of stresses, stiffness, natural frequency and percentage weight savings.
\end{abstract}

Keywords: Analysis ${ }^{1}$, Composite $^{2}$, Material $^{3}$, stress $^{4}$, weight $^{5}$

\section{Introduction of Modeling}

Solid modeling is the first step for doing any $3 \mathrm{D}$ analysis and testing, it also gives 3D physical picture for new products. FE models can be created easily from solid models by the process of meshing. Solid models can be prepared as testing models by giving this in "stl" format to rapid prototyping machines. Rapid prototyping models give opportunity to show the model or assembly in presentation before it is manufactured. FE models can be manually for simple cases only. But if the model is of complex form (or) shape then, the only way for preparing FE model is "meshing the solid model" using a suitable computer program.Commercially available solid modeling packages are

$>$ I-DEAS

$>$ CREO

$>$ UNIGRAPHICS

In the present work both steel and mono amalgamated composite Leaf Spiral is designed using CREO software. is used to analyze both steel and amalgamated composite Leaf Spiral.

\subsection{SOLID MODELING}

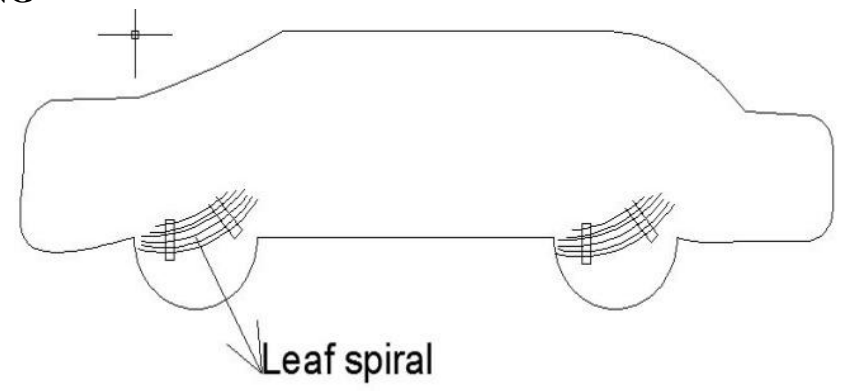

Fig: 1. Leaf spiral representation 
In the present work, mono steel Leaf Spiral and mono amalgamated composite Leaf Spirals are modeled. For modeling the amalgamated composite Leaf Spiral, the dimensions of a conventional mono steel Leaf Spiral using in passenger vehicle are considered. Since the Leaf Spiral is symmetrical about the neutral axis, only half of the spring is modeled by considering it as a cantilever beam. Load is applied at the base of the Leaf Spiral in the middle in downward direction.

\subsection{MODELING PROCEDURE (STEEL LEAF SPIRAL)}

Modeling of steel Leaf Spiral is done using CREO 5.0 cad software by considering the dimensions of existing Leaf Spiral used in passenger vehicle. Since the Leaf Spiral is symmetrical about the neutral axis, only half part of the Leaf Spiral is modeled by considering it as a cantilever beam. A point load is applied at the middle of the Leaf Spiral in downward direction. The solid model of steel Leaf Spiral is shown in the Fig. 1.

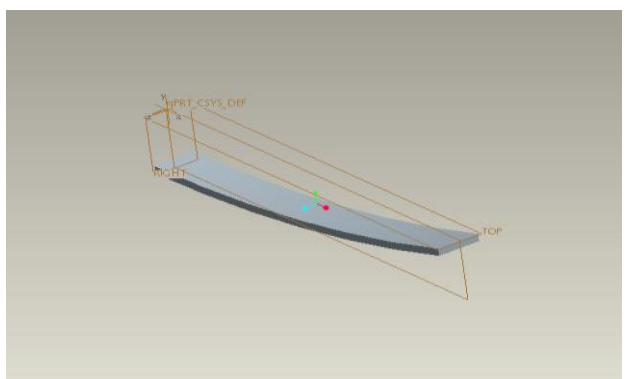

Fig. 2. Solid Model of Steel Leaf Spiral

\subsection{SPECIFICATIONS FOR STEEL LEAF SPIRAL}

Specifications of existing mono steel Leaf Spiral used in passenger vehicle is shown in table 1.Table.1. Specifications of Steel Leaf Spiral

\begin{tabular}{|c|c|c|}
\hline S. No & Parameters & Value \\
\hline 1. & Total length of the spring(Eye to Eye), 2L & $970 \mathrm{~mm}$ \\
\hline 2. & Free camber (At no load condition) & $66 \mathrm{~mm}$ \\
\hline 3. & No. of full length leaves (Master Leaf), $\mathrm{N}_{\mathrm{f}}$ & 2 (Both side) \\
\hline 4. & Thickness of leaf, $\mathrm{t}$ & $12 \mathrm{~mm}$ \\
\hline 5. & Width of Leaf Spiral, b & $60 \mathrm{~mm}$ \\
\hline 6. & Maximum load given on spring, W & $2190.15 \mathrm{~N}$ \\
\hline 7. & Young's Modulus of Leaf Spiral, E & $2.0 \mathrm{e} 5 \mathrm{~N} / \mathrm{mm}^{2}$ \\
\hline 8. & Weight of Leaf Spiral & $3.5 \mathrm{Kg}$ \\
\hline
\end{tabular}

\subsection{STATIC ANALYSIS}

A static analysis calculates the effects of steady loading conditions on a structure, while ignoring inertia and damping effects, such as those caused by time-varying loads. A static analysis can, however, include steady inertia loads (such as gravity and rotational velocity), and time-varying loads that can be approximated as static equivalent loads (such as the static equivalent wind and seismic loads commonly defined in many building codes). If the stress values obtained in the analysis crosses the allowable values it result in the failure of the structure in the static condition itself. To avoid such a failure, this analysis is necessary. Static analysis determines the displacements, stresses, strains, and forces in structures or components caused by loads that do not induce significant inertia and damping effects. Steady loading and response conditions are assumed; that is, the loads and the structure's response are assumed to vary slowly with respect to time. The types of loading that can be applied in a static analysis include:

$>$ Externally applied forces and pressures

$>$ Steady-state inertial forces (such as gravity or rotational velocity)

$>$ Imposed (nonzero) displacements

$>$ Temperatures (for thermal strain)

$>$ Fluences (for nuclear swelling)

Static analysis is performed by considering pre-determined conditions (i.e boundary conditions \& point load) using software. The procedure is explained step by step as follows

Step 1 Preferences $\rightarrow$ Structural $\rightarrow$ Discipline $\rightarrow$ Option h-Method $\rightarrow$ O.K

Step 2 Preprocessor $\rightarrow$ Element type $\rightarrow$ Add/Exit/Delete $\rightarrow$ Add $\rightarrow$ Solid $\rightarrow$ Brick 8node $45 \rightarrow$ O.K $\rightarrow$ Close.

International Conference on Recent Innovations in Civil \& Mechanical Engineering $21 \mid$ Page [i- CAM2K16] DOI: 10.9790/1684-16053032028 
Step 3 Preprocessor $\rightarrow$ Material Properties $\rightarrow$ Material Model $\rightarrow$ Structural $\rightarrow$ Linear $\rightarrow$ Elastic $\rightarrow$ Isotropic $\rightarrow$ Enter Material Properties $\rightarrow$ O.K

Step 4 Preprocessor $\rightarrow$ Meshing $\rightarrow$ Size controls $\rightarrow$ Manual size $\rightarrow$ Global $\rightarrow$ size $\rightarrow 5 \rightarrow$ O.K

Step 5 Preprocessor $\rightarrow$ Meshing $\rightarrow$ Mesh tool $\rightarrow$ Mesh $\rightarrow$ Pick all $\rightarrow$ O.K

Step 6 Preprocessor $\rightarrow$ Loads $\rightarrow$ Define Loads $\rightarrow$ Apply $\rightarrow$ Structural $\rightarrow$ Displacement $\rightarrow$ On Nodes $\rightarrow$ Pick Box $\rightarrow$ Select UZ $\rightarrow$ O.K.

Step 7 Preprocessor $\rightarrow$ Loads $\rightarrow$ Define Loads $\rightarrow$ Apply $\rightarrow$ Structural $\rightarrow$ Displacement $\rightarrow$ On Nodes $\rightarrow$ Pick Box $\rightarrow$ All $\mathrm{DOF} \rightarrow$ O.K.

Step 8 Preprocessor $\rightarrow$ Loads $\rightarrow$ Define Loads $\rightarrow$ Apply $\rightarrow$ Structural $\rightarrow$ Force $\rightarrow$ On Nodes $\rightarrow$ Select node $\rightarrow$ Enter the Value $\rightarrow$ O.K.

Step 9 Solution $\rightarrow$ Analysis Type $\rightarrow$ New Analysis $\rightarrow$ Static $\rightarrow$ O.K.

Step 10 Solution $\rightarrow$ Solve $\rightarrow$ Current LS $\rightarrow$ O.K $\rightarrow$ Close.

Step 11 General post processor $\rightarrow$ Plot Results $\rightarrow$ Contour Plots $\rightarrow$ Nodal Solution $\rightarrow$ DOF Solution $\rightarrow$ Displacement Vector Sum $\rightarrow$ Deformed Shape Only $\rightarrow$ Auto calculated $\rightarrow$ O.K.

Step 12 General post processor $\rightarrow$ Plot Results $\rightarrow$ Contour Plots $\rightarrow$ Nodal Solution $\rightarrow$ Stress $\rightarrow$ Von Mises- Stress $\rightarrow$ Deformed Shape Only $\rightarrow$ Auto calculated $\rightarrow$ O.K.

The Amalgamated models of three different composite Leaf Spirals are shown from Fig.2

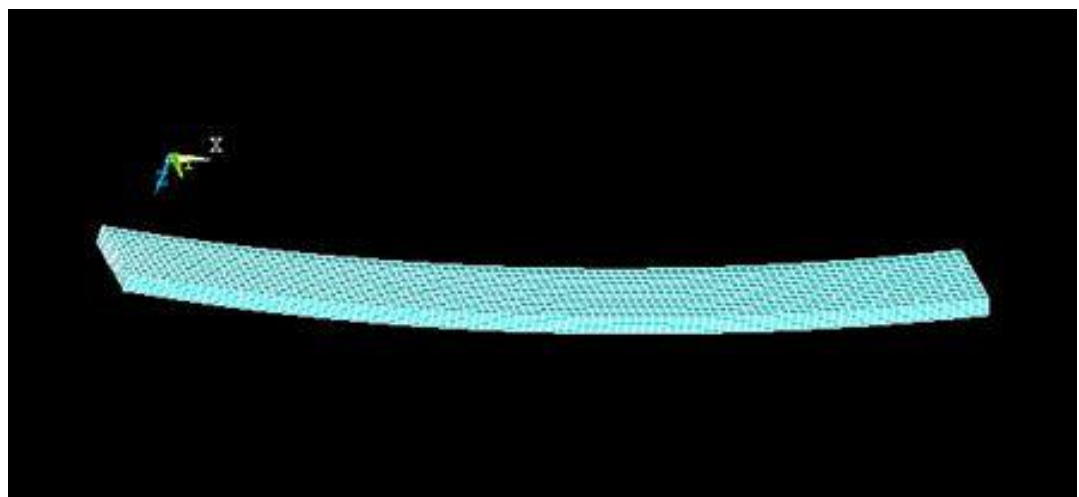

Fig. 3. Amalgamated Model of Composite-3 Composite Leaf Spiral

\subsection{ANALYSIS OF STEEL LEAF SPIRAL}

Analysis of steel Leaf Spiral is carried out using analysis software, to analyze the stresses by performing static analysis for the given Leaf Spiral specification. And the results are verified whether they are within the desirable limits or not. Analysis involves discretization called meshing, applying boundary conditions and loading. In the present work, analysis is carried out by restricting the camber height to half of its original value.

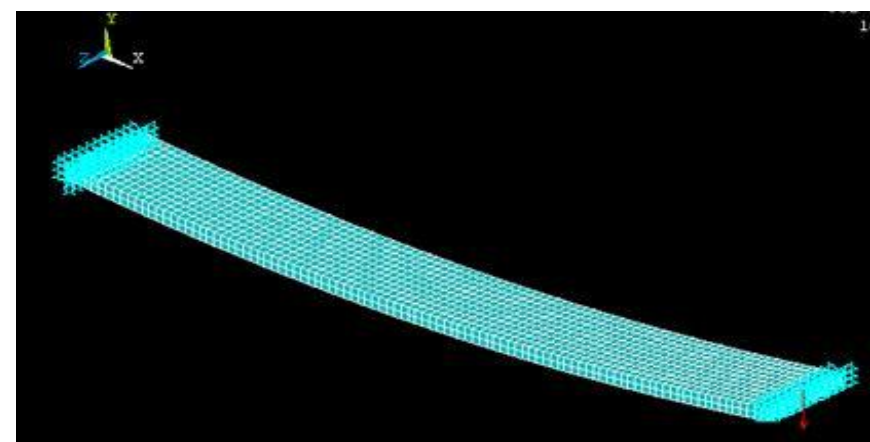

Fig. 4. Meshed Model of Steel Leaf Spiral with Boundary Conditions

\subsection{ANALYSIS OF MONO AMALGAMATED COMPOSITE LEAF SPIRAL}

To perform the analysis, the dimensions of amalgamated composite Leaf Spirals are considered same as that of steel spring. Analysis of mono amalgamated composite Leaf Spirals (i.e E-Glass/Epoxy, SGlass/Epoxy, and Carbon /Epoxy) are carried out using by considering four lamina, each of thickness $2.5 \mathrm{~mm}$, and with fiber orientation angle as $0^{0}$. The element chosen for analysis is shell 99. 
Material properties of composite materials are shown in table .2 .

Table.2. Material Properties of Composite Materials

\begin{tabular}{|l|l|l|l|}
\hline \multicolumn{1}{|c|}{ Material properties } & \multicolumn{1}{|c|}{ Composite-1 } & \multicolumn{1}{c|}{ Composite- 2} & \multicolumn{1}{c|}{ Composite -3} \\
\hline Fiber Volume Fraction, $\%$ & 55 & 55 & 55 \\
\hline Extensional Elastic Modulus, $\mathrm{E}_{1} \mathrm{MPa}$ & $39 \mathrm{E}+4$ & $43 \mathrm{E}+4$ & $142 \mathrm{E}+4$ \\
\hline Transverse Elastic Modulus, $\mathrm{E}_{2} \mathrm{MPa}$ & $8.6 \mathrm{E}+4$ & $8.9 \mathrm{E}+4$ & $10.3 \mathrm{E}+4$ \\
\hline In-plane Shear Modulus, $\mathrm{G}_{12} \mathrm{MPa}$ & $3.8 \mathrm{E}+4$ & $4.5 \mathrm{E}+4$ & $7.2 \mathrm{E}+4$ \\
\hline Major Poisson's Ratio, $v_{12}$ & 0.29 & 0.28 & 0.28 \\
\hline Minor Poisson's Ratio, $v_{21}$ & 0.08 & 0.08 & 0.03 \\
\hline Density, $\rho \mathrm{kg} / \mathrm{mm}^{3}$ & $2.1 \mathrm{E}-5$ & $2 \mathrm{E}-5$ & $1.58 \mathrm{E}-6$ \\
\hline
\end{tabular}

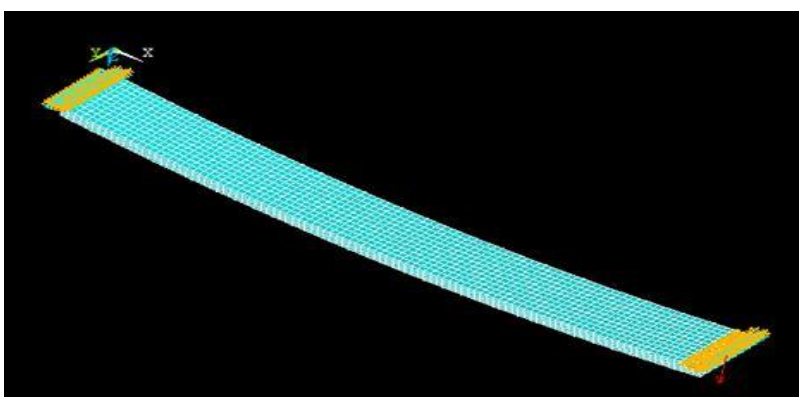

Fig. 5. Meshed Model of Mono Amalgamated Composite Leaf Spiral with Boundary Conditions.

\section{Results And Discussion}

The results of Static and Modal analysis of both steel and mono amalgamated composite Leaf Spirals (i.e Composite-1, Composite-2and Composite-3).Static analysis of steel Leaf Spiral is performed using analysis software, by considering the pre-determined conditions (necessary boundary conditions and loads) to achieve the results with in the allowable limits. From the static analysis, deflection and Von-mises stress of steel Leaf Spiral are $37.01 \mathrm{~mm}$ and $489.87 \mathrm{MPa}$. The results are shown from fig.5.0 to 5.2. The obtained results are with in the allowable limits. Static analysis of amalgamated composite Leaf Spiral is performed using analysis software, by considering four lamina, each of thickness $2.5 \mathrm{~mm}$ and different fiber angle orientations to achieve the results (deflections and stresses) within the desirable limits. Finally a best stacking sequence or fiber angle of $360^{\circ}$ is achieved by making several attempts. From the results of static analysis of mono amalgamated composite Leaf Spiral, the displacements of the Composite-1, Composite-2, Composite-3 are $45.78 \mathrm{~mm}, 41.57 \mathrm{~mm}$ and 11.79 $\mathrm{mm}$. And the corresponding Von-Mises stress values are 258.45 MPa, 257.48 MPa and 259.99 MPa. The results are shown in below figures.From the modal analysis, the natural frequency of steel Leaf Spiral is found to be $1.072 \mathrm{~Hz}$. While that of amalgamated composite Leaf Spirals (i.e Composite-1, Composite-2and Composite-3) are $1.488 \mathrm{~Hz}, 1.59 \mathrm{~Hz}$ and $3.199 \mathrm{~Hz}$. And the results are shown in following figures.

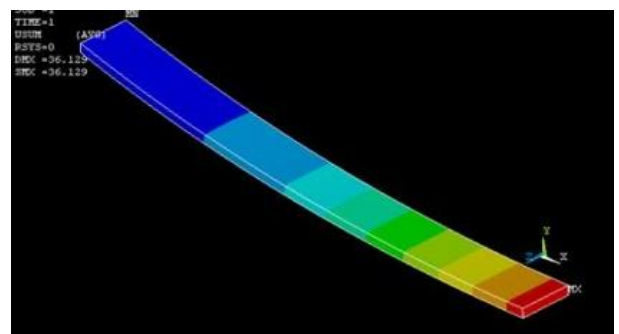

Fig. 6. Deflection Plot of Steel Leaf Spiral

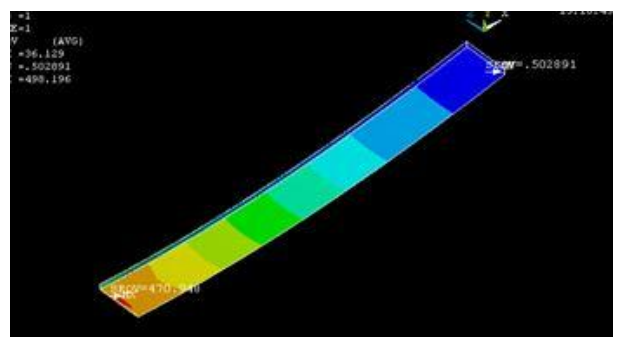

Fig. 7. Von-Mises Stress Plot of Steel Leaf Spiral 


\subsection{AMALGAMATED COMPOSITE LEAF SPIRAL}

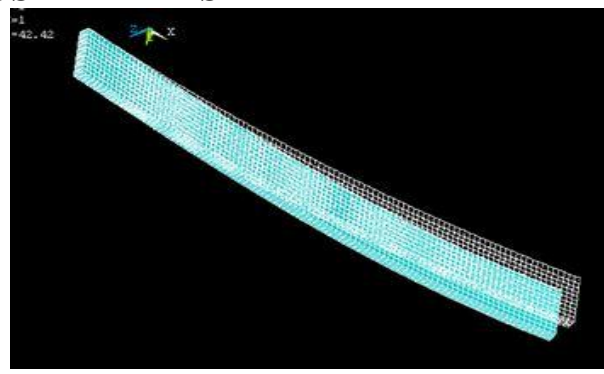

Fig. 8. Deformed and Unreformed Plot of Composite-1 Amalgamated Composite Leaf Spiral

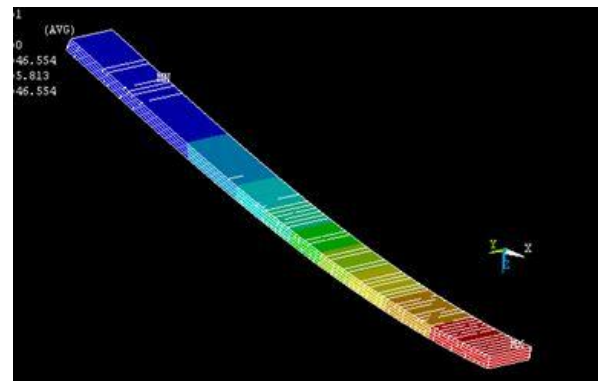

Fig. 9. Deflection Plot of Composite-1 Amalgamated composite Leaf Spiral

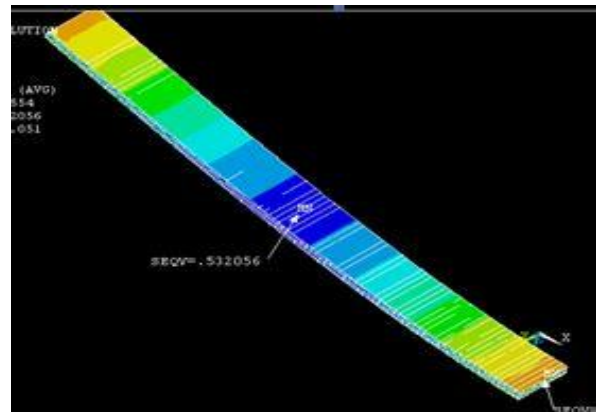

Fig.10. Von-Mises Stress Plot of E- Glass / Epoxy Amalgamated Composite Leaf Spiral

\subsection{COMPOSITE-2AMALGAMATED COMPOSITE LEAF SPIRAL}

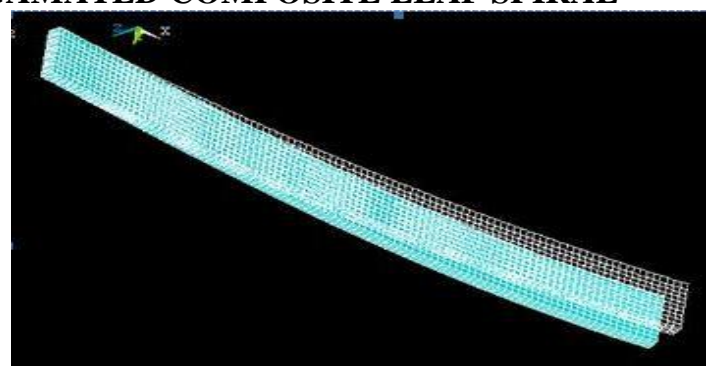

Fig. 11. Deformed and Unreformed Plot of Composite-2Amalgamated Composite Leaf Spiral

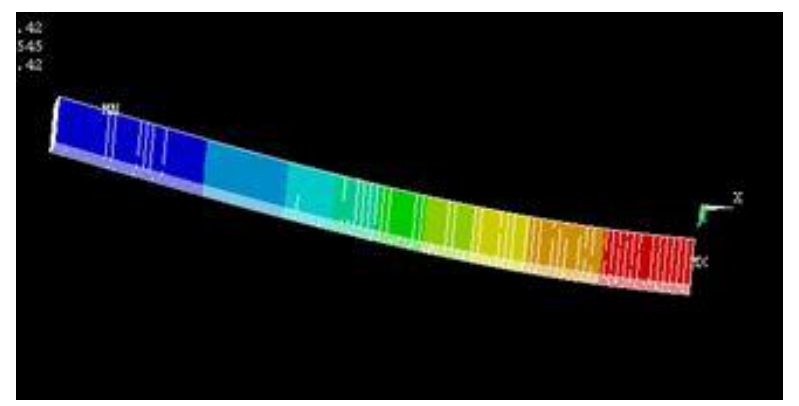

Fig. 12. Deflection Plot of Composite-2Laminated composite Leaf Spiral 


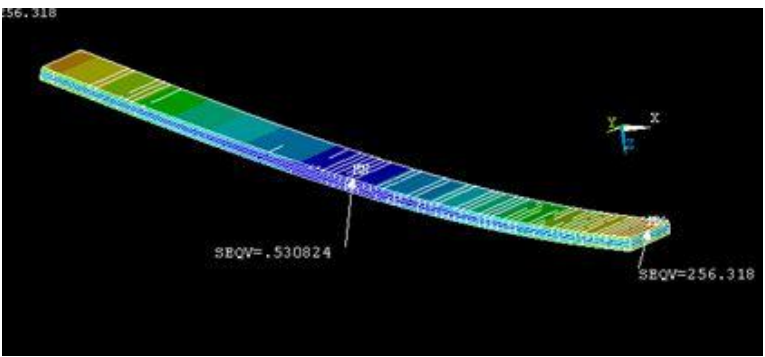

Fig. 13. Von-Mises Stress Plot of Composite-2Amalgamated Composite Leaf Spiral

\subsection{COMPOSITE-3 AMALGAMATED COMPOSITE LEAF SPIRAL}

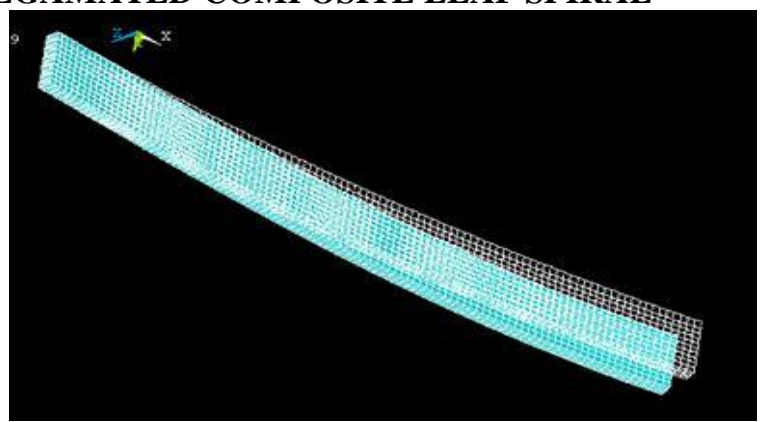

Fig. 14. Deformed and Unreformed Plot of Composite-3 Amalgamated Composite Leaf Spiral

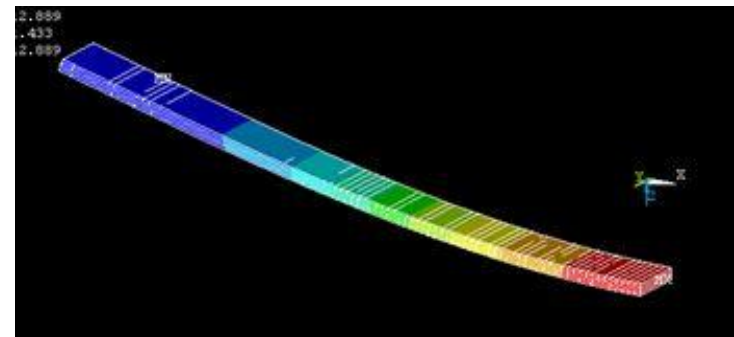

Fig. 15. Deflection Plot of Composite-3 Amalgamated Composite Leaf Spiral

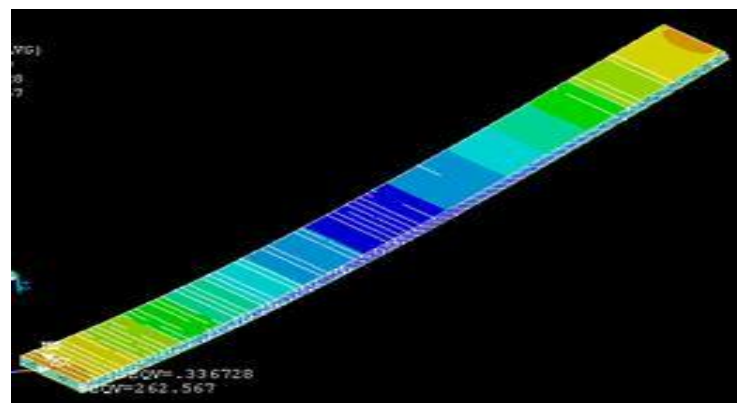

Fig. 16. Von-Mises Stress Plot of Composite-3 Amalgamated Composite Leaf Spiral

\subsection{MODAL ANALYSIS outline PLOTS}

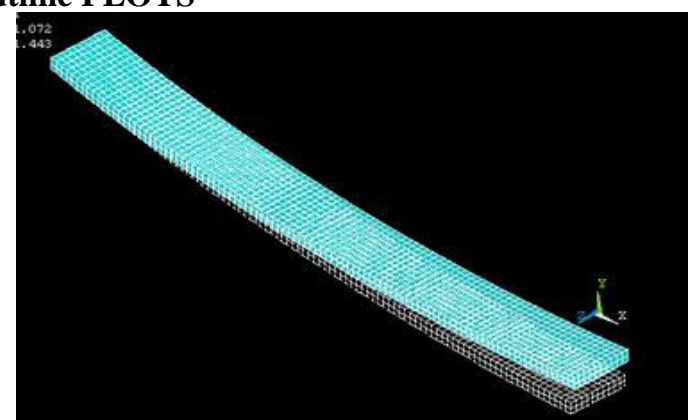

Fig. 17. Natural Frequency Plot of Steel Leaf Spiral 


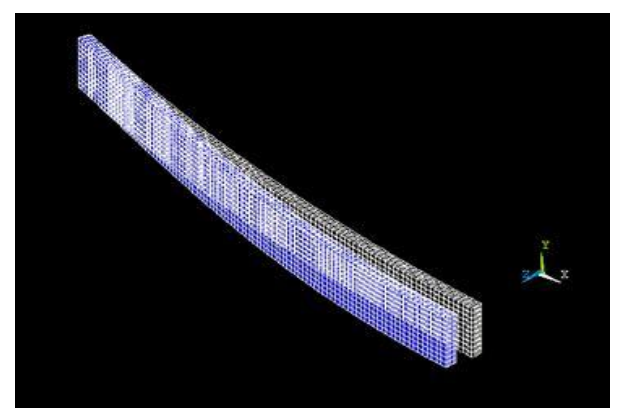

Fig. 18. Natural Frequency Plot of Composite-1 Amalgamated Composite Leaf Spiral

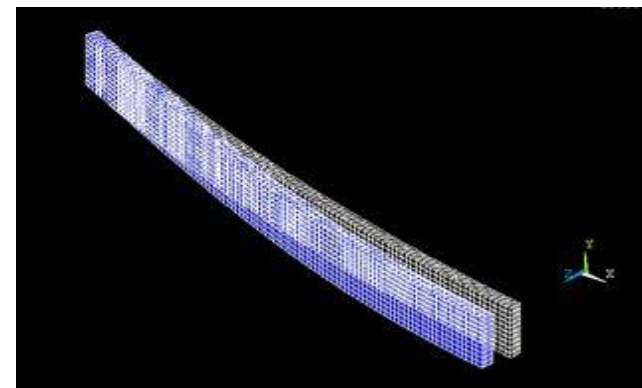

Fig.19. Natural Frequency Plot of Composite-2Amalgamated Composite Leaf Spiral

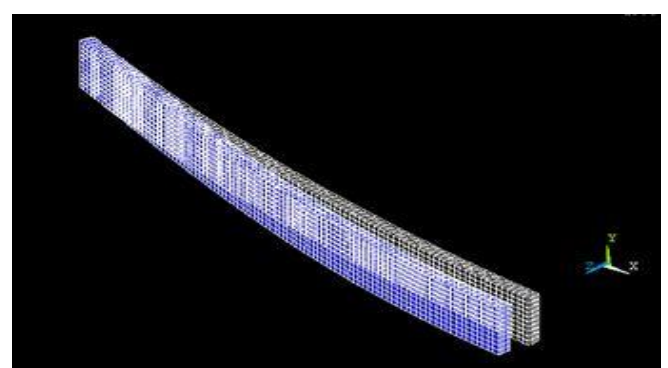

Fig. 20. Natural Frequency Plot of Composite-3 Amalgamated Composite Leaf Spiral

\subsection{ANALYTICAL RESULTS}

Analytical results obtained for conventional steel \& amalgamated mono composite Leaf Spirals using is shown in the table 3 .

Table 3. Analytical Results

\begin{tabular}{|c|c|c|c|c|}
\hline Material Type & Fiber Orientation & $\begin{array}{c}\text { Deflection } \\
(\mathbf{m m})\end{array}$ & \multicolumn{2}{|c|}{$\begin{array}{c}\text { Stress(Mega Pascal) } \\
\text { Maximum }\end{array}$} \\
\hline Steel & & 35.148 & 489.145 & 0.503 \\
\hline Composite-1 & $(0,0,0,0)$ & 45.37 & 249.95 & 0.5324 \\
\hline Composite-2 & $(0,0,0,0)$ & 41.542 & 261.754 & 0.5308 \\
\hline Composite-3 & $(0,0,0,0)$ & 11.754 & 271.542 & 0.3367 \\
\hline
\end{tabular}

\subsection{RESULTS SHOWING THE PERCENTAGE OF WEIGHT REDUCTION}

Weight of Leaf Spiral is reduced by the replacement of steel one with composite materials. And the percentage of weight reduction is calculated and is shown in the table 4 .

Table 4. Percentage of Weight Reduction

\begin{tabular}{|c|c|c|}
\hline Material & Weight $(\mathbf{K g})$ & Percentage of Weight Reduction \\
\hline Steel & 3.69 & $-1 .---$ \\
\hline Composite-1 & 1.241 & 75 \\
\hline Composite-2 & 0.984 & 78.99 \\
\hline Composite-3 & 0.758 & \\
\hline
\end{tabular}

Mono amalgamated composite Leaf Spiral reduces the weight by $73 \%$ for Composite-1, $75 \%$ for Composite2and $78.99 \%$ for Composite-3. 
The weight of the Leaf Spiral is reduced considerably about $82 \%$ by replacing steel Leaf Spiral with Composite3 amalgamated composite Leaf Spiral.

\subsection{GRAPHS}

From the graphs, we can observe the displacements and stresses of amalgamated composite Leaf Spirals (i.e Composite-1, Composite-2\& Composite-3) are less compared to steel spring. Below Fig indicates the loaddeflection curves, below fig. indicates the load von-mises stress curves.

\section{Load Vs Deflection}

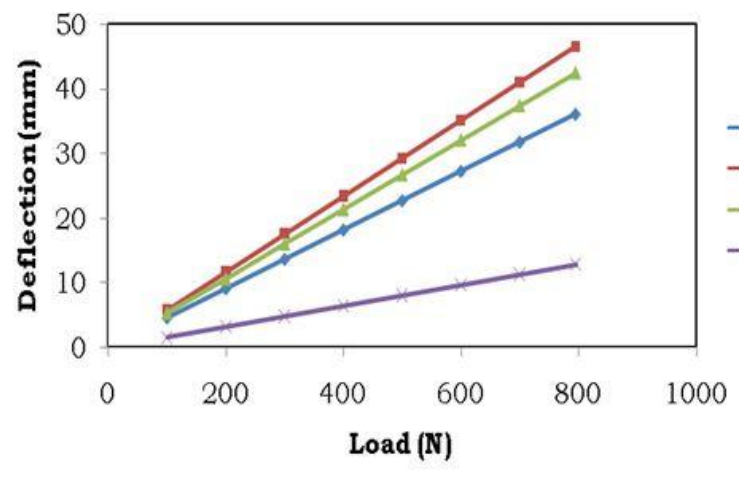

Fig: graph among steel, composite-1, composite-2 and composite-3

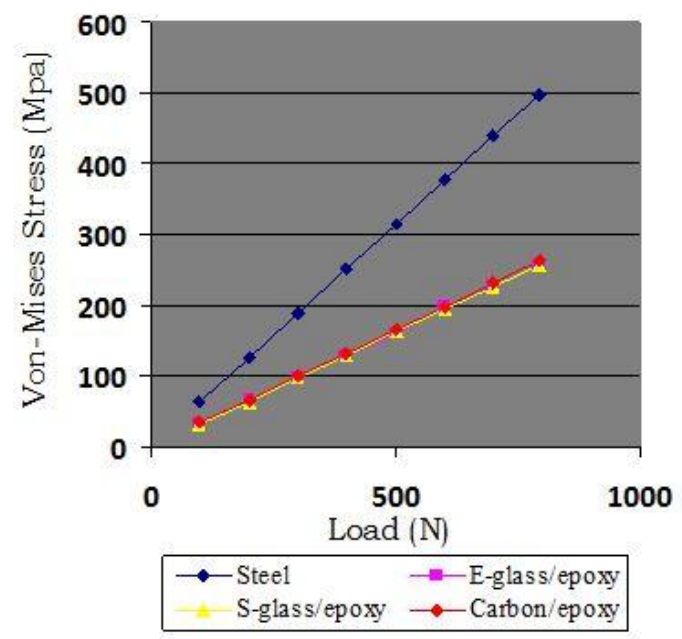

Fig: Load-Von-Mises Stress for steel and lamianted composite Leaf Spiral

\section{Conclusion}

$\checkmark \quad$ The replacement of steel Leaf Spiral with amalgamated composite Leaf Spiral leads to the following conclusions.

$\checkmark \quad$ From the static analysis results, it is observed that the von-mises stress in the steel Leaf Spiral is 500.2 MPa. And that of amalgamated one (i.e in Composite-1, Composite-2and Composite-3) are 261.04 MPa, 249.12 $\mathrm{MPa}$, and 271.52 MPa.

$\checkmark$ The mono amalgamated composite Leaf Spiral is modeled for the same stiffness as that of the steel Leaf Spiral. It is found that the stiffness of all the composite Leaf Spirals is more when compared with that of steel Leaf Spiral. The stiffness of steel Leaf Spiral is $23.37 \mathrm{~N} / \mathrm{mm}$ and similarly stiffness of Composite-1, Composite-2and Composite-3 composite Leaf Spirals are $18.05 \mathrm{~N} / \mathrm{mm}, 18.64 \mathrm{~N} / \mathrm{mm}$ and 62.59 N/mm respectively.

$\checkmark$ Convectional steel Leaf Spiral was found to weigh $3.9 \mathrm{~kg}$ where as mono amalgamated (i.e Composite-1, Composite-2and Composite-3) composite Leaf Spirals are found to weigh $1.013 \mathrm{~kg}, 0.965 \mathrm{~kg}$ and $0.762 \mathrm{~kg}$. The percentage of weight reduction is $73 \%$ for Composite-1, $74.68 \%$ for Composite-2and $80.54 \%$ for Composite-3.

$\checkmark \quad$ For the modal analysis, same boundary conditions are applied without considering the load. Determination

International Conference on Recent Innovations in Civil \& Mechanical Engineering $27 \mid$ Page [i-CAM2K16] DOI: 10.9790/1684-16053032028 
of natural frequencies and the mode shapes are important parameters in the design of a structure for dynamic loading conditions.

$\checkmark \quad$ The natural frequency of the steel Leaf Spiral is found to be $1.801 \mathrm{~Hz}$ and similarly natural frequency of Composite-1, Composite-2and Composite-3 amalgamated composite Leaf Spirals are found to be $1.480 \mathrm{~Hz}$, $1.552 \mathrm{~Hz}$ and $3.198 \mathrm{~Hz}$.

$\checkmark$ Composite-3 amalgamated composite Leaf Spiral can be suggested for replacing the steel Leaf Spiral from stress, stiffness and weight point of view.

$\checkmark$ From the analysis it is concluded that Composite-3 amalgamated composite Leaf Spiral performing better than steel and other composite materials as considered in this study.

\section{SCOPE FOR FUTURE WORK}

$\checkmark$ Amalgamated composite Leaf Spiral can be designed by using metal matrix composites.

$\checkmark$ Deflection of amalgamated composite Leaf Spiral is reduced by increasing the thickness of lamina.

\section{References}

[1]. Sri Harsha et al done static analysis of steel leaf spring and laminated composite multi leaf spring using carbon fibre reinforced polymer.

[2]. Patunkar et al made comparative analysis of conventional steel leaf spring with a virtual model of a composite leaf spring under static load condition.

[3]. GulurSiddaramanna et al made general study on design and analysis of a low cost fabrication of complete mono composite leaf spring and mono composite leaf spring with bonded end joints. 